\title{
Leitura dramática e jogo teatral a partir da dramaturgia para crianças e jovens: possibilidades de fruição na escola
}

\author{
Dramatic reading and theatrical play based on dramaturgy for children and young people: possibilities of \\ reduction in school
}

\section{Fabiano Tadeu Grazioli}

Universidade Regional Integrada do Alto Uruguai e das Missões - URI - Erechim - Rio Grande do Sul - Brasil

\begin{abstract}
Resumo: No presente artigo, propomos atividades que possam ser realizadas na escola, utilizando-se do texto dramatúrgico, nosso objeto de pesquisa desde que iniciamos os estudos em nível de pós-graduação lato sensu, e, logo em seguida, strictu senso, concluindo doutorado em Letras no último ano e defendendo tese sobre dramaturgia infantil. Buscamos dos meios cênicos a prática conhecida como leitura dramática, fundamentando-a com detalhes a partir de Patrice Pavis (2007), Marta Metzler (2006) e Andréa Maria Favilla Lobo (2011), no intuito de provocar os mediadores de leitura a realizá-la no contexto da sala de aula. Depois, propomos a criação de jogos teatrais a partir de textos dramatúrgicos e, após tratar brevemente sobre o jogo teatral, seu surgimento e seus princípios, a partir de Viola Spolin $(2001,2008)$, Ingrid Koudela (2006) e Ricardo Japiassu (2001), dispomo-nos a explicar seu funcionamento e a demonstrar de que modo a dramaturgia escrita pode dar margem à criação de tais jogos, uma iniciativa que julgamos nossa, haja vista não termos percebido sua divulgação no meio acadêmico, nem na área da Literatura, nem na área das Artes Cênicas. Como sugestão ao professor, relacionamos diversos jogos que podem ser propostos a partir de um conjunto significativo de peças teatrais com as quais temos entrado em contato nos últimos anos. Assinalamos, assim, as possibilidades reais de aproveitamento do texto dramatúrgico nas práticas de leitura na escola, como uma possibilidade de o gênero dramático fazer-se presente nos momentos nos quais a intenção é a formação de um leitor que consiga interagir com a diversidade de textos que a literatura oferece atualmente.
\end{abstract}

Palavras-chave: Leitura dramática. Jogo teatral. Leitura da dramaturgia.

Abstract: In the present article we propose activities that can be performed at school using the dramaturgical text. Furthermore, this has been our research object since we started the studies at postgraduate level, lato sensu, and soon after, strictu senso, completing a doctorate in Letters last year in which I defended a thesis on children's dramaturgy. We sought from the scenic media the practice known as dramatic reading to provoke reading mediators to perform it in the classroom context and it was based on details from Patrice Pavis (2007), Marta Metzler (2006), Andréa Maria Favilla Lobo (2011). First, we proposed the creation of theatrical games from dramaturgical texts after briefly dealing with theatrical play, approaching its emergence and its principles from Viola Spolin (2001, 2008), Ingrid Koudela (2006) and Ricardo Japiassu (2001). Then, we explained how it works and how the written play can help in the creation of such games. It is important to mention that this was our initiative as we have noticed a lack of its dissemination in the academic field, including the Literature field and Performing Arts. Therefore, as a suggestion from the professor, we have related several games that can be proposed from a significant set of plays that we have been in contact within recent years. Thus, we point out suggestions of how to use the dramaturgical text in reading practices at school as a dramatic genre possibility especially, when it is focused on the reader's training. So, the reader can interact with a diversity of texts offered by the Literature.

Keywords: Dramatical reading. Teatral game. Dramaturgy reading. 


\section{Introdução}

Em um passado muito recente, não era comum que um texto dramático fosse lido por uma criança ou por um adolescente, nem que fizesse parte de uma atividade de leitura proposta pela escola, que não fosse a encenação do texto, prática que, apesar das parcas condições que a maioria das escolas possuía, acontecia (e acontece). Nas últimas décadas, os textos para teatro começaram a aparecer nas bibliotecas escolares, principalmente por meio dos programas de leitura pleiteados pelos governos. Além da encenação, tais textos, pelo projeto gráfico e ilustrativo que apresentam, passam a exigir um leitor que realize uma leitura do texto impresso, seja aquela silenciosa e introspectiva, seja em práticas alternativas de leitura propostas pelos professores.

É visível e considerável, no campo que se desenha, o empenho de algumas editoras em oferecer ao mercado textos dramáticos no formato de livros atraentes para o leitor, com ilustrações que em nada perdem para os textos narrativos e poéticos e com projetos gráficos ricos esteticamente, verdadeiros facilitadores da leitura dos textos.

Nesse contexto, favorável às práticas de leitura com o texto dramatúrgico, muitas vezes têm faltado aos professores informações sobre esse gênero literário, sua história, sua estrutura, sua estética, sua leitura (questões que somente em um artigo não conseguimos atender), mas, principalmente, sobre as atividades que podem ser projetadas a partir desse gênero na escola. Eis a demanda que o presente artigo pretende, minimamente, atender. Em um contexto de práticas de leitura que se tem mostrado favorável à diversidade dos gêneros literários na escola, e, por isso mesmo, a pensar sobre o teatro infantil e a leitura da dramaturgia no contexto escolar, acreditamos que seja importante a proposição de um artigo que discuta de que maneira as atividades em torno do texto

\footnotetext{
1 Para citar alguns projetos que desenvolvemos em panorama nacional e que receberam espaço importante nas comunidades nas quais foram realizados: Leitura dramática: revelando a dramaturgia brasileira para jovens leitores e suas comunidades (a partir da Bolsa Funarte de Circulação Literária 2010-2011); Dramaturgia e jovens leitores: encontros necessários nos territórios da cidadania (a partir da Bolsa Biblioteca
}

dramático podem-se fazer presentes no referido contexto, quais seriam essas atividades e como podem ser desenvolvidas, principalmente nas aulas de Arte, Língua Portuguesa e Literatura.

Tendo o texto dramático conseguido ultrapassar os muros da escola, no que diz respeito à publicação, à seleção, ao investimento financeiro (compra, por parte do governo), entre outros, e chegado às mãos dos professores e dos alunos, o que é possível ou necessário realizar? O que é possível ou necessário fazer? De modo bastante simplista, poderíamos responder: ler ou encenar, ou seja, realizar a leitura silenciosa ou realizar a montagem do espetáculo cênico. Mas essas atividades não levam em consideração outras possibilidades que vão ao encontro da natureza de um gênero com características tão específicas como temos evidenciado em vários estudos, possibilidades muitas vezes colocadas em prática junto à formação de professores e aos próprios leitores ${ }^{1}$.

Longe de apresentarmos uma receita de como trabalhar com o texto dramatúrgico em sala de aula de modo a desconsiderar o contexto em que cada professor que entrar em contato com esta escrita está inserido e de impor atividades sob o crivo do "correto" e do "errado" -, este artigo apresenta caminhos para o professor realizar outras atividades, que não sejam as mais óbvias (leitura silenciosa e encenação) e que já são realizadas na escola (com uma série de ressalvas, diga-se de passagem). Nossa proposta é que o texto dramatúrgico seja motivo para a realização da atividade conhecida como leitura dramática, a qual fundamentamos a partir dos estudos de Patrice Pavis (2007), Marta Metzler (2006) e Andréa Maria Favilla Lobo (2011) e de nossas experiências com tal metodologia. Além disso, propormos a criação de jogos teatrais, tendo como base os enredos de alguns textos dramatúrgicos destinados às crianças e aos jovens. Nosso ponto de partida são os estudos de Viola

Nacional/FUNARTE de Circulação Literária 2012-2013); SESC Mais Leitura - 2012, entre outros. Temos agregado, nos últimos anos, às metodologias que utilizamos na docência na graduação e na especialização a leitura dramática e os jogos teatrais baseados em textos dramatúrgicos. 
Spolin (2001, 2008), criadora dos jogos teatrais, Ingrid Koudela (2006), principal estudiosa da obra de Spolin no Brasil, e Ricardo Japiassu (2001). Seguem, nas próximas seções, as duas alternativas que propomos.

\section{Leitura dramática ou dramatizada}

Atividade que surgiu no meio teatral, a leitura dramática ou dramatizada ${ }^{2}$ pode ser aproveitada nas aulas de Artes, Língua Portuguesa e Literatura como um recurso potencializado para os alunos conhecerem e interagirem significativamente com textos dramatúrgicos. De modo bastante simplificado, a leitura dramática é a leitura em voz alta de textos escritos para o teatro. Nosso objetivo, nesta seção, é apresentar ao leitor este recurso, sua dinâmica e características.

Entre o texto dramático e a encenação, há um longo caminho a ser percorrido pelos artistas. No meio teatral, a leitura dramática situa-se no início da referida trajetória e diferencia-se do espetáculo teatral que, além da palavra, utiliza os recursos que compõem a visualidade da cena: os gestos, o figurino, o cenário, a música, a iluminação. Patrice Pavis (2007, p. 228), ao nomear tipos de leitura dramática, afirma que, quando a leitura dramática ocorre dessa maneira, sendo "[...] o processo de aprendizagem do texto, bem no início dos ensaios", ela é chamada de vocalização. Contudo, com o passar do tempo, a leitura dramática tornou-se uma atividade a ser apresentada a uma plateia. Segundo Pavis (2007, p. 228), "[...] a apresentação de uma peça nova sem cenário nem figurino" é chamada de espacialização.

É comum, atualmente, atores e diretores organizarem sessões de leitura dramática abertas ao público, não somente como um exercício para suas funções, ou teste dos autores para seus novos textos, mas principalmente como objeto de fruição para o público. Marta Metzler, no texto Leitura dramatizada: objeto de fruição - instrumento de estudo (2006), cita diversos projetos que visaram a realizar a leitura dramática de textos teatrais em apresentações públicas na cidade do Rio de Janeiro. E observando a dinâmica de tais eventos, a pesquisadora traz, a nosso ver, uma definição importante de leitura dramática:

[...] constitui-se na apresentação pública de uma leitura de texto teatral, em que atores interpretam uma peça ou parte dela com o texto em mãos. Em geral há um diretor da apresentação que define como ela se dará, podendo priorizar ou o poder de visualidade e ação da palavra, quando os atores interpretam sentados ou de pé, sem movimentação (neste caso, frequentemente leem-se também as rubricas); ou a cena, quando o diretor cria algumas marcações que substituem a leitura de rubricas, e, em alguns casos, sugere figurinos, objetos cenográficos, trilha sonora, iluminação. (METZLER, 2006, p.231).

A definição da autora, embora se diferencie um pouco da referida por Pavis, traz ao leitor informações necessárias para o entendimento do funcionamento da atividade que queremos propor. A primeira forma apresentada por Metzler é o modo de apresentação mais simplificado, pois, conforme percebemos, não existem marcações de cenas como na segunda, nem outros elementos que não seja o texto.

Metzler ainda acrescenta que "[...] a preparação da leitura inclui um breve estudo do texto e do autor pelo diretor e pelo elenco; seleção de partes do texto que serão lidas, quando não é possível apresentá-lo na íntegra; escalação do elenco e organização dos ensaios." (METZLER, 2006, p.231). Nota-se que a apresentação do texto para o público não é, de modo algum, o primeiro contato dos atores com a peça escrita. Requer estudo das cenas, dedicação em ensaios, assim como a presença do diretor cumprindo sua função, que é, de modo geral, a de ajudar cada ator a descobrir a dramaticidade de sua personagem, a entonação necessária e as inflexões verbais usadas para dizer o texto, as expressões faciais ou um gesto econômico que pode pontuar a cena. Todos esses cuidados são tomados para que a palavra fique em evidência:

Quando a opção do diretor se faz pela ausência de ação física dos atores, ausência de cenário, figurino e quando 0 uso da iluminação não pretende impor um conceito

\footnotetext{
${ }^{2}$ As duas expressões referem-se à mesma atividade. Neste texto, usaremos a expressão "leitura dramática".
} 
cênico, mas unicamente possibilitar a visibilidade do palco, evidencia-se a palavra. Todos - elenco e público - estão concentrados nela [...]. Quando, diferentemente, o diretor cria marcações, elas não são esboços de uma possível encenação, não chegam a configurar uma concepção de cena [...] e em geral são criadas apenas para dinamizar a leitura. Em qualquer dos casos, portanto, a via principal de comunicação com o público é a palavra. Por isso, a leitura dramatizada é uma atividade em que, por definição, a dramaturgia é elemento central. (METZLER, 2006, p.232).

A centralidade da dramaturgia também é apontada por Andréa Maria Favilla Lobo (2011, p. 44), para quem o texto dramatúrgico torna-se fundamental na leitura dramática,

[...] não só em termos do conteúdo a ser analisado e lido em voz alta, mas também como objeto cênico, ou seja, o texto se torna um objeto cênico indispensável, sua presença é visível, e a ação de se ler em cena é uma prática que não deve, em hipótese alguma, ser dissimulada por parte dos atores. Em outras palavras, decorar o texto não é algo imprescindível, mas sim realizar uma boa leitura em cena.

Cabe destacar que a "boa leitura" - ou seja, a leitura dramática realizada adequadamente - por si só coloca a dramaturgia em evidência, pois desperta o público para o texto em questão. Além disso, a referida prática de leitura convida o público a buscar em sua imaginação os elementos que complementam a cena, como as ações descritas no texto, cenários, figurinos, efeitos de iluminação e som.

Vistos os aspectos que julgamos essenciais sobre a leitura dramática, vamos tratar da referida atividade no contexto escolar. Podem as aulas tornarem-se momentos para sua realização? Podem as salas de aula ou as escolas tornarem-se espaços para apresentações de leitura dramática?

Nossa proposta, desde que começamos os estudos na área da dramaturgia e da leitura, é de que a leitura dramática, sem sofrer retaliações, seja transposta para a sala de aula. Os atores a quem os autores referem-se descrevendo a dinâmica da atividade em questão podem ser os alunos, o diretor pode ser o professor, a dinâmica prevista para a preparação da atividade pode acontecer na sala de aula e o resultado pode ser apresentado na turma ou mesmo para toda a escola.

O professor, conhecedor das preferências temáticas, do nível de amadurecimento da turma ou dos projetos a serem desenvolvidos na escola, deve selecionar os textos dramáticos a serem estudados e, depois, apresentados. O estudo do texto e a preparação (o ensaio) das atividades são chamados por nós de Oficinas de leitura dramática. A apresentação do texto na turma ou para toda a escola, de Sessões de leitura dramática. Nas oficinas, o primeiro passo é realizar uma leitura do texto escolhido junto com os alunos, a fim de estudá-lo.

Depois que a turma se inteirou do texto, percorreu suas cenas, discutiu sua temática, seu enredo, personagens, entre outros, o professor e os alunos podem organizar grupos de acordo com o número de personagens. Tomemos como exemplo o texto dramático Meus olhos são teus olhos, de Flávia Savary (2011). Nesse texto, as personagens são Olho de fora, Olho de dentro, Menina e Beto (Roberto Pié). A seguir, transcrevemos a sinopse que encontramos na contracapa do livro:

A menina não quer ver nada. Nem montanha, nem sonho, nem fada. Por que será? Beto quer ser o maior cantor do rock do mundo, transforma-se em elefante, orangotango e mamolongo. $O$ que acontece quando esses dois personagens se encontram? Nesta peça, Flávia Savary transporta o leitor para um mundo cheio de fantasia e imaginação, levando-o a perceber que olhar para fora de si e também para dentro exige, às vezes, uma boa dose de coragem e outra de esforço. (SAVARY, 2011, contracapa).

O livro possui ilustrações singelas de Alexandre Rampazo. Pelas personagens inusitadas (Olho de fora e Olho de dentro), esse texto coloca-se como um desafio aos encenadores, à medida que não é tão simples conceber visualmente e fisicamente personagens tão peculiares. Assim, torna-se um exercício interessante para os alunos imaginarem, na leitura dramática, tais personagens e as ações que realizam.

No caso de Meus olhos são teus olhos, os grupos devem ser de cinco alunos, as quatro personagens e um aluno para ler as rubricas, que, 
nesse texto, são muitas e de fundamental importância para o entendimento do enredo. É importante que um grupo inicie os trabalhos e seja dirigido pelo professor, que deve chamar atenção para aspectos da leitura do texto, servindo de motivação/exemplo para os demais grupos. Um detalhe importante nesse estágio do trabalho é o professor instigar os alunos com perguntas como "Que intenção a personagem transmite ao dizer determinada frase?", "Como ela deve ser dita, tendo em vista a intenção da personagem na cena?", "Que nuances ela deve transmitir?" Tais perguntas provocam os alunos para adentrarem no texto e encontrarem o tom ideal para a prolação dos diálogos. Essas provocações não valem para o aluno que lerá as rubricas. Ele deverá realizar uma leitura "limpa" do texto, ou seja, sem as intenções que os demais atores devem imprimir em suas falas, de preferência em um ritmo um pouco mais rápido do que leria naturalmente. Sugerimos que o professor faça o estudo que propomos com todo o texto e, em seguida, permita que cada grupo inicie o trabalho de leitura. Sua função, nesse momento, é auxiliar os grupos individualmente. Ao chegar ao final do texto, cada grupo pode expor suas dúvidas e, em seguida, reiniciar as atividades de leitura. É importante realizar pelo menos três leituras antes de a oficina se transformar em uma sessão de leitura dramática.

Quando o professor julgar adequado, os grupos podem realizar a leitura para toda a turma. Pode-se dividir as salas em palco e plateia de modo muito simples: no palco, ficam as cadeiras para os alunos/atores e, do outro lado, ficam as cadeiras da plateia. Cada grupo apresenta-se e, no final, o professor propõe uma conversa sobre o desempenho do grupo, que pode envolver os alunos que também assistiram à leitura. Meus olhos são teus olhos, de Flávia Savary, é um texto curto, ideal para o início dos trabalhos com leitura dramática.

$\mathrm{Na}$ prática, com a leitura dramática sempre encorajamos nossos alunos e atores a encontrarem na maneira de dizer o texto a intenção de cada fala, a

\footnotetext{
3 Viola Spolin utiliza o termo "jogadores" para designar os participantes do jogo, prefere este termo a atores. Quanto à idade dos jogadores, a autora afirma que crianças a partir dos sete/oito anos de idade podem participar do jogo teatral, pois são capazes
}

intenção da personagem, o subtexto, como alguns diretores estão acostumados a dizer, possibilidades essas que revelam a intenção do autor. Assim, a poética da voz de que trata o simpósio em que o trabalho foi apresentado no IX Colóquio Internacional Leitura e Cognição pode ser alcançada e experimentada, fruída e aproveitada nos seus benefícios mais importantes, pelo ator que diz o texto (pois ele também vive uma experiência única $\mathrm{e}$ potencializada com a dramaturgia) e pelo ouvinte, sua plateia, componente do processo que nos acostumamos a ver, muitas vezes, como único capacitado e interessado nesses benefícios.

\section{0 jogo teatral a partir do texto dramatúrgico}

Uma das atividades nas quais apostamos, quando se trata de levar a dramaturgia escrita para a sala de aula, é a criação e exploração de jogos teatrais a partir de textos dramatúrgicos. Antes de passarmos a alguns exemplos da categoria de jogos que propomos, trataremos sobre o jogo teatral, seu surgimento, sua sistemática e sua contribuição para o indivíduo e para a escola.

Os jogos teatrais foram concebidos originalmente pela diretora norte-americana Viola Spolin, por volta das décadas de 1940 e 1950. Seu objetivo era ensinar técnicas teatrais a jovens estudantes nas suas oficinas. A proposta da autora não se constitui em um compilado de exercícios que mostram aos jogadores ${ }^{3}$ um projeto fechado e pronto de atuação. Preocupa-se Spolin em oferecer um conjunto significativo de atividades a partir das quais os participantes possam assimilar elementos importantes da arte teatral, utilizando improvisações. "Por meio do jogo e de soluções de problemas, técnicas teatrais, disciplinas e convenções são absorvidas organicamente, naturalmente e sem esforço pelos alunos" (SPOLIN, 2001, p.20), afirma ela sobre o sistema de atuação que criou.

de utilizar a linguagem artística do teatro e expressar-se por meio dela. 
Já segundo Ricardo Japiassu (2001, p. 17), professor de Teatro da Universidade do Estado da Bahia,

[...] o fato dos desafios cênicos formulados por Spolin serem apresentados como jogos com regras permite que os alunos se apropriem de conceitos teatrais, prazerosamente, em sala de aula. Além disso, assegura a oportunidade para uma interação ativa, espontânea e verdadeira por parte de todos.

Os jogos teatrais são, ao mesmo tempo, divertimento e exercícios que possibilitam o treinamento das habilidades teatrais. Na construção da linguagem cênica, os jogadores estabelecem com o grupo uma relação intensa, que combina imaginação criadora com observação e obediência de regras dos jogos propostos.

Mas que especificidades esse tipo de jogo possui? O jogo teatral desenvolve-se a partir de uma estrutura estabelecida, que é formada pelo Quem, pelo Onde e pelo $O$ quê. Definindo cada parte da estrutura, Spolin afirma que o Quem são as personagens; o $O$ quê é a parte da estrutura que envolve uma atividade mútua entre os atores, uma razão para a personagem estar em determinado lugar; e o Onde é o ambiente geral e imediato de uma cena ${ }^{4}$. Por exemplo:

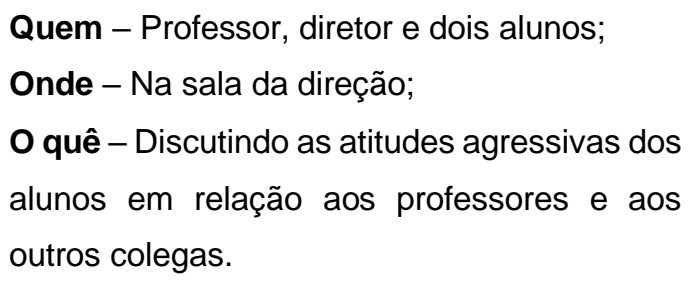

Nota-se que, com os elementos acima, tem-se a estrutura necessária para que o jogo teatral aconteça. O elemento Como (que falta no esquema de Spolin) não deve ser planejado previamente, pois não faz parte da estrutura inicial da cena. Deve ser improvisado, ou seja, ele é a cena desenvolvendo-se, articulando-se, por isso, deve ser "enfrentado" (para usar um termo da própria Spolin) no momento em que aparece. O Como "[...] deve surgir das relações do palco, como num jogo. Deve acontecer no palco (aqui e agora!)". (SPOLIN, 2008, p. 31). Quando a autora utiliza a expressão "palco", ela não está se referindo somente ao espaço formal do palco cênico. Spolin utiliza a expressão de maneira mais ampla, de modo que significa o lugar no qual os jogos teatrais podem acontecer: a sala de aula, a biblioteca, o pátio, o salão, o refeitório, o centro comunitário, entre outros.

O Ponto de Concentração (POC) é parte importante no sistema dos jogos teatrais e significa que os jogadores devem manter o foco naquilo que foi préestabelecido. O envolvimento com o POC resulta no relacionamento entre os atores, e esse relacionamento é a cena improvisada que surge. Cabe lembrar que faz parte da proposta de Spolin que o grupo de indivíduos que joga seja dividido em "times" que se alternam nas funções de "jogadores" e de "público", ou seja, enquanto um grupo joga, outro grupo assiste, e viceversa.

Ingrid Koudela (2006), professora da Escola de Comunicação e Artes da Universidade de São Paulo e responsável pela tradução brasileira das obras de Viola Spolin, é autoridade nas pesquisas e publicações sobre jogo teatral no Brasil. Tratando sobre a evolução do jogo teatral, a pesquisadora afirma:

Por meio do envolvimento criado pela relação de jogo, o participante desenvolve liberdade pessoal dentro do limite de regras estabelecidas e cria técnicas e habilidades pessoais necessárias para o jogo. À medida que interioriza essas habilidades e essa liberdade ou espontaneidade, ele se transforma em um jogador criativo. (KOUDELA, 2006, p. 43).

Segundo Koudela, ao se entregar ao jogo e ao vivê-lo com intensidade, o jogador torna-se criativo e vai dominar cada vez mais as técnicas teatrais. Contudo, os benefícios do jogo não se limitam ao aprimoramento das referidas técnicas. Eles transcendem o espaço inicial - o palco - e influenciam na vida cotidiana do jogador:

Jogos teatrais, experimentados em sala de aula, devem ser reconhecidos não como diversões que extrapolam necessidades curriculares mas sim como suportes que podem ser tecidos no cotidiano, atuando como

\footnotetext{
4 SPOLIN, Viola. Improvisação para o teatro. São Paulo: Perspectiva, 2008. Definições compiladas de várias páginas.
} 
energizadores e/ou trampolins para todos. Inerente a técnicas teatrais, são comunicações verbais, não-verbais, escritas, não-escritas. Habilidades de comunicação desenvolvidas e intensificadas por meio de oficinas de jogos teatrais com o tempo, abrangem outras necessidades curriculares e da vida cotidiana. (SPOLIN, 2001, p. 20).

Os princípios que Spolin prevê para os jogos teatrais, quando transportados para o espaço escolar, lembram o ambiente e a atmosfera de ensino e aprendizagem que (assim como muitos colegas) idealizamos para a escola, ambiente no qual a espontaneidade, a descoberta e a criatividade impulsionam a convivência e as experiências de aprendizagem:

Para além das necessidades curriculares, os jogos teatrais trazem momentos de espontaneidade [...]. Aqui/agora é o tempo da descoberta, da criatividade, do aprendizado. Ao participar dos jogos teatrais, professores e alunos podem encontrar-se como parceiros, no tempo presente e prontos para comunicar, conectar, responder, experienciar, experimentar e extrapolar, em busca de novos horizontes. (SPOLIN, 2001, p. 20).

É por isso que pesquisadores, professores de arte e artistas insistem na possibilidade de os jogos teatrais fazerem parte das aulas das diversas disciplinas do currículo escolar, principalmente daquelas que trabalham com as linguagens artísticas, como Artes, Língua Portuguesa e Literatura. Mas, e os textos dramatúrgicos, que ligação têm eles com os jogos teatrais? Nossa provocação é que o professor, conhecedor da dramaturgia destinada à infância e à juventude, possa aproveitá-la para a construção de jogos teatrais. As informações para o "preenchimento" da estrutura proposta por Spolin (2008) podem ser recuperadas dos textos dramatúrgicos, nas suas cenas ou na sua totalidade. Essa proposta, novidade até a primeira publicação que fizemos sobre o tema, em 2015, é uma ideia nossa, desde sempre praticada em nossas oficinas, junto a alunos, em aulas de literatura, ou a atores, em workshops de jogos teatrais. Quando da publicação do primeiro material sobre a proposta, contratamos a consultoria da Professora Doutora Ingrid Koudela, atualmente docente aposentada do ECA/USP, já citada neste trabalho, que recomendou com entusiasmo a nossa concepção. De acordo com Koudela (2015, s.p.), a interseção entre jogos teatrais e literatura dramática seria uma prática enormemente enriquecedora para o processo de criação dos primeiros e acrescentaria uma nova dimensão ao trabalho em sala de aula.

Para exemplificar nossa proposta, tomemos o texto dramático O menino detrás das nuvens (1997), de Carlos Augusto Nazareth, que recebeu o Selo Altamente Recomendável da Fundação Nacional do Livro Infantil e Juvenil (FNLIJ), no ano posterior a sua publicação. $O$ referido texto recebeu nova edição em 2014, pela Habilis Press, com ilustrações de Dani D' Angeli, transformando-se, pela primeira vez, em um livro ilustrado, nos moldes que temos definido esse produto cultural contemporâneo em nossos estudos, a partir dos trabalhos de Peter Hunt (2010) e de Maria Nikolajeva e Carole Scott (2011), e que não serão aproveitados neste estudo por falta de espaço. Algumas rubricas foram revistas com nossa ajuda, quando, na época, exercíamos a função de coordenador editorial de literatura infantil e juvenil da editora e nos propusemos a revisar o texto com vistas a oferecê-lo ao jovem leitor com mais possibilidades quando do delineamento dos cenários, figurinos e principalmente da movimentação das cenas, algo que, acreditávamos, deveria ser revisto para a recepção do texto por meio de um livro ilustrado. Logo no início do livro (o da primeira edição), o autor apresenta a sinopse, que transcrevemos a seguir:

O Menino detrás das nuvens conta a história de Zezinho, um menino que tem um enorme desejo em seu peito, uma grande vontade de saber o que existe além dos morros, além daquilo que seus olhos alcançam. E um "bolo" no peito que ele não sabe muito bem identificar. Só sabe que é seu destino conhecer esse sentimento e resolver esse "bolo". Menino de um universo restrito, seu contato com o resto do mundo é seu padrinho Malaquias, que promete levá-lo para conhecer "o outro lado". Seu desejo de ir é imenso. Mas seu padrinho morre. E seu desejo, ao invés de morrer com seu padrinho, renasce forte. Tão forte que o faz "voar" até o outro lado do morro. E aí descobre a magia e a arte. Primeiro uma cigana, depois o circo. E aí se descobre artista. Descobre que o seu desejo de ver o outro lado é a sua possibilidade de ver o mundo de um jeito diferente da maioria das pessoas, e que seu destino é mostrar ao mundo esse jeito especial 
de ver a vida; com seu olhar de artista, seu eterno olhar de menino. É uma saga do herói, numa viagem de aprender. Herói comum de todos os dias, de todos os meninos que buscam cumprir seu destino. (NAZARETH, 1997, p. 5).

Conhecendo a obra, podemos desmembrá-la em diversas cenas e visualizar diversos jogos teatrais a partir delas. Logo no início, quando Zezinho e Sinhana, sua mãe, conversam sobre o "bolo" que o menino carrega no peito, podemos estruturar um jogo:

Quem - Dona Sinhana (mãe) e Zezinho (filho);

Onde - No pátio da casa, na zona rural;

O quê - Em uma conversa afetuosa, Zezinho tenta explicar à mãe sua angústia, o "bolo" que carrega no peito.

Mais adiante, da cena em que Sinhana e Zezinho recebem a visita de Seu Malaquias, podemos aproveitar a seguinte estrutura:

Quem - Sinhana (mãe), Zezinho (filho) e Seu Malaquias (padrinho);

Onde - Na varanda da casa de Sinhana;

O quê - Seu Malaquias conta às demais personagens suas peripécias, dando exemplos de como é o mundo para além dos morros, e as personagens fazem perguntas, interessadas.

Quando Zezinho deixa o mundo conhecido e "voa" para conhecer o que tem do lado de lá dos montes, ele encontra uma Cigana. A personagem desperta no menino o encantamento de quem prevê o futuro e olha o mundo com magia. A Cigana, na história, provoca o menino para pensar sobre os diversos modos de olhar o mundo. Dessa cena, podemos retirar a seguinte estrutura de jogo teatral:

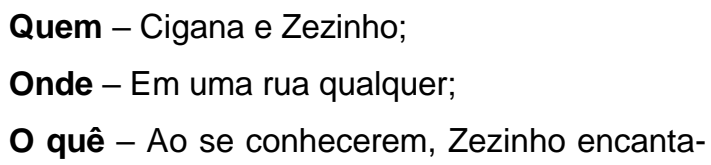
se com o modo de pensar da Cigana, e ela propõe ao menino que mude seu olhar de triste e cinza para alegre e colorido.
Como demonstramos, aproveitando as diferentes personagens $e$ as cenas do texto dramatúrgico de Nazareth, o professor pode retirar a estrutura necessária para diversos jogos teatrais. Outros jogos podem ser criados a partir do texto: as cenas de Zezinho no circo, a descoberta de seu dom de artista (palhaço), o retorno para sua casa e seu reencontro com Sinhana são outras cenas que podem ser aproveitadas. Nosso objetivo foi exemplificar e não esgotar as possibilidades.

$\mathrm{Na}$ sequência, escolhemos sete textos dramatúrgicos e sugerimos jogos teatrais a partir deles. Nossa proposta é trazer ao professor algumas ideias de como os textos podem ser aproveitados, na perspectiva dos jogos de regras ou teatrais.

\section{Festa no céu, de Maria Viana}

\section{Jogo teatral 1:}

Quem - Bem-te-vi, Quero-Quero e Canário;

Onde - Na floresta;

O quê - Procuram uma solução para o problema do Mestre Sapo, que não possui asas e quer ir até o céu.

\section{Jogo teatral 2:}

Quem - Dom Urubu e Mestre Sapo;

Onde - No céu;

O quê - Em pleno voo, ao perceber que Mestre Sapo escondeu-se em seu violão, Dom Urubu pretende derrubar a personagem. Mestre Sapo tenta convencê-lo do contrário.

\section{O Cavalinho Azul, de Maria Clara Machado} Jogo teatral 1:

Quem - Pai e mãe de Vicente (menino, protagonista);

Onde - Em frente à casa da família;

O quê - Conversam sobre a venda do cavalo do menino. O pai quer vender e dar ao menino um brinquedo. A mãe não aceita a ideia.

\section{Jogo teatral 2:}

Quem - Vicente e Menina (sua companheira de jornada em busca do Cavalinho Azul); 
Onde - Em um lugar qualquer;

O quê - Debatem hipóteses de onde esteja o Cavalinho Azul, que foi vendido pelo pai de Vicente.

\section{Bonequinha de pano, de Ziraldo}

\section{Jogo teatral 1:}

Quem - Pitucha (a bonequinha de pano, sozinha);

Onde - No sótão da casa da avó de Leninha, dona da boneca, onde Pitucha se encontra guardada;

O quê - Constrói um breve monólogo; no qual reclama que Leninha, sua dona, há muito tempo não aparece para brincar ${ }^{5}$.

\section{Jogo teatral 2:}

Quem - Leninha (mulher de aproximadamente 30 anos) e Pitucha (a boneca de pano);

Onde - No sótão da casa da avó de Leninha;

O quê - Brincam e relembram a infância de Leninha, que tinha Pitucha como sua amiga inseparável.

\section{A herança, Olga Reverbel}

\section{Jogo teatral 1:}

Quem - Freira Gertrudes (60 anos), Marylín (artista fracassada, 40 anos), Marva (feiticeira, sem idade informada), Rockluz (hippie, 18 anos), Scarface (traficante, 37 anos), debutante enlouquecida (16 anos);

Onde - Salão do castelo de Porcovil;

O quê - Discutem freneticamente a divisão da grande herança do irmão das personagens, Tiburciano Gouveia.

\section{Jogo teatral 2:}

Quem - Os irmãos listados no jogo anterior;

Onde - Salão do castelo de Porcovil;

O quê - Reagem ao fato de Tiburciano Gouveia ter deixado a herança para uma pessoa que não era da família.

As aventuras de um Diabo Malandro, de Maria Helena Kuhner

\footnotetext{
${ }^{5}$ Oportunidade para o jogador improvisar sozinho em cena.
}

\section{Jogo teatral 1:}

Quem - Capitolino (capitão) e Comandante (ambos humanos);

Onde - Um planeta distante, perdido por aí, segundo a autora;

O quê - Organizam-se para explorar o planeta desconhecido; no qual acabam de chegar.

\section{Jogo teatral 2:}

Quem - Capitolino, Comandante, Moça (suneviana, habitante do planeta explorado na história) e Diabo;

Onde - No planeta referido no jogo anterior;

O quê - Disputa (verbal e gestual) dos bens do novo planeta (rio, árvores frutíferas etc.).

\section{Uma ratinha apaixonada, de Júlio Emílio Braz Jogo teatral 1:}

Quem - Ratinho, Ratinha, Mãe e Pai da Ratinha;

$$
\begin{aligned}
& \text { Onde - Na floresta; } \\
& \text { O quê - Ratinho e Ratinha tentam convencer os }
\end{aligned}
$$
Pais da Ratinha que eles se amam e que, por isso, querem casar. Os pais da personagem são absolutamente contra, pois o Rato é muito fraco.

\section{Jogo teatral 2:}

Quem - Pai e Mãe da Ratinha, Sol;

Onde - Casa do Sol;

O quê - Pai e mãe da Ratinha insistem com 0 Sol para que ele se case com a Ratinha, porque ele é forte. No final do jogo, o Sol indica o Temporal para o casamento.

Observação: O mesmo jogo pode se repetir com as personagens Temporal, Vento, Rochedo, Touro e Cordame. O Sol, no final do jogo, nega definitivamente o pedido e diz que mais forte do que ele é o Temporal, que nega o pedido e indica Vento para o matrimônio. O Vento não aceita e indica o Rochedo, que indica o Touro, e este indica o Cordame. Por fim, o Cordame indica o Ratinho. Esse é basicamente o enredo da peça, que pode ser 
conhecido por meio dos jogos teatrais, alternando as personagens conforme descrito.

\section{A Rosa que gira a roda, de Flávia Savary Jogo teatral 1:}

Quem - Eufrásio Hermenegildo (caixeiro viajante) e moradora de Vila Aurora;

Onde - Em frente à casa da moradora;

o quê - Eufrásio Hermenegildo procura convencer a moradora de que seus tecidos são os melhores que ela pode adquirir, em relação à qualidade e ao preço. A moradora, desconfiada, faz uma série de perguntas e observações e, assim, o jogo se desenvolve.

\section{Jogo teatral 2:}

Quem - Rosa (menina cantadora de pregões) e Boi (que puxa uma carroça);

Onde - Em um lugar qualquer (neutro);

O quê - Rosa, na sua jornada em busca da "roda que gira a vida de volta ao povo de Vila Aurora", encontra o Boi e pergunta se ele conhece a Mainha, a Rainha da Roda. Boi e Rosa desenvolvem um diálogo. No final, o Boi dá uma dica para que a personagem procure o Trem (dividido em locomotiva e vagões ${ }^{6}$ ), que possivelmente terá a resposta.

Observação: O mesmo jogo pode se repetir com as personagens 001 (funcionário de uma fábrica ${ }^{7}$ ), Padroeira de Vila Aurora e Roda de samba (um conjunto de, pelo menos 3 sambistas). Rosa desenvolve, com as personagens citadas, um diálogo a partir da pergunta "Você conhece Mainha, rainha da roda?" e, no final do diálogo, a personagem dá uma dica para a menina procurar a personagem seguinte, e assim até chegar à Mainha.

Para finalizar esta seção do trabalho, cabem algumas considerações gerais sobre o jogo teatral e a nossa proposta:

- Esperamos que esteja claro para o professor e demais mediadores de leitura que, na estrutura, o elemento $O$ quê são as coordenadas gerais para que a cena aconteça e que o Como surge no

\footnotetext{
${ }^{6}$ Oportunidade para o jogador improvisar sozinho em cena.
}

momento da improvisação. Portanto, sabe-se $O$ quê a cena contém e improvisa-se o Como ela se desenrola;

É importante que o professor forme os times de acordo com o número de personagens de cada jogo e que possibilite que, enquanto um grupo joga (apresenta-se) mantendo o POC na estrutura combinada, os demais times assistam, bem como prevê Spolin;

- Depois de cada time apresentar-se, é importante realizar uma avaliação, segundo recomendação da criadora do sistema de jogos teatrais. A avaliação pode ser orientada por perguntas como: O time manteve o foco na estrutura combinada? As personagens mostraram ou contaram a história? Houve improvisação a partir da estrutura? Os diálogos e ações apresentados surgiram de maneira espontânea e criativa?

- O tempo de duração do jogo pode ser determinado pelo professor ou pode ser estabelecido a partir de outros critérios (como ter atingido determinado nível de troca entre os jogadores);

- Os jogos teatrais que apresentamos partem de uma proposta de diálogo, como pode ser percebido na leitura. Mas, a partir dos diálogos que se estabelecem entre os jogadores (o Como), a expressão corporal surge naturalmente. Assim, os jogos teatrais acontecem na confluência da expressão verbal e da expressão corporal;

- Para os alunos menores, que ainda não têm condições de ler o texto dramatúrgico, é importante que o professor conte a história, alternando com a leitura de algumas partes e, depois que a turma conhecer a história, proponha os jogos. Nesse contexto, os jogos teatrais são uma oportunidade de os alunos brincarem com a história, adentrando, através da linguagem do teatro, no mundo criado pelo dramaturgo.

- Para os alunos que já conseguem realizar a leitura das peças de teatro, os jogos teatrais podem servir para envolvê-los no clima do texto dramático a ser lido. Ou então servem para que o aluno, depois de conhecer a peça, explore ainda mais a atmosfera

\footnotetext{
7 Remete à figura de Carlitos, no filme Tempos Modernos.
} 
criada pelo dramaturgo e já conhecida na leitura. Servem também para a preparação ("treinamento", diria Spolin) para a possível encenação da peça, em um trabalho que descreveremos em outra oportunidade.

Muitos jogos teatrais da categoria que apresentamos foram propostos por nós em oficinas de leitura dramática, justamente para ajudar alunos e atores a encontrarem nuances, detalhes, modos de dizer e expressar apropriados às personagens dos textos dramatúrgicos que poderiam ser aproveitadas depois, quando das experimentações em busca do modo mais adequado de dizer ou proferir as falas. Muitas vezes, um elemento potencializador da leitura dramática, uma fagulha que seja, que trará para trabalho com o texto uma performance específica, uma chama, para continuarmos no nível das analogias, foi encontrado ou encontrada na realização do jogo teatral. Isso demonstra uma relação entre as duas atividades que investigamos e propomos neste trabalho.

\section{Considerações finais}

Nosso objetivo, neste artigo, foi o de apresentar duas possibilidades de o texto dramatúrgico transitar pelo espaço escolar, por meio de uma escrita acessível a professores e demais mediadores de leitura interessados na temática abordada, pois sabemos que o gênero literário aqui focalizado ainda se encontra distante das práticas de leitura promovidas pela escola. Tratando, agora, pontualmente, das atividades que propomos, cabe afirmar que não é novidade a leitura dramática ficar condicionada às práticas cênicas, ao círculo dos dramaturgos, diretores, encenadores e atores e que não temos visto ela romper essas barreiras e chegar ao espaço escolar ou demais espaços de mediação de leitura. Quanto ao jogo teatral, embora ele também seja uma prática dos meios cênicos (surgiu, inclusive, com Spolin, nesse contexto) é mais presente na escola, embora, infelizmente, sua teoria não seja conhecida nem assimilada de maneira ampla pela escola brasileira, de modo geral. Essa distância que ainda existe entre atividades de leitura dramática e jogos teatrais e a escola (e os demais espaços de leitura) justifica os caminhos que apresentamos neste artigo, bem como a novidade que propomos em relação aos jogos teatrais, a de buscar os elementos para a estrutura dos jogos nos textos dramatúrgicos.

Agora, no fechamento, cabe destacar que o texto literário terá, na escola, o destino que nós, professores e demais mediadores de leitura, dermos a ele. Nossos alunos conhecerão a literatura a partir das metodologias que nós empreendermos. $E$, nesse contexto, cabe a nós, professores, encontrarmos um espaço para que o gênero dramático seja conhecido, lido (considerando as suas características e sua natureza singular: nasce para ser transformado em um espetáculo, por isso a importância das atividades de leitura dramática, já que elas asseguram essa característica intrínseca da dramaturgia) e jogado (no sentido que propomos a partir de Viola Spolin).

Como percebido no artigo, aproveitamos o texto dramatúrgico com suas características específicas, que, por isso mesmo, tem muito a contribuir na formação de um leitor, cuja instrução é tarefa na qual a escola não tem-se saído muito bem: aquele habilitado a interagir com o texto dramatúrgico. Desajustes à parte, é oportuno afirmar nossa crença na escola, enquanto espaço apropriado para os indivíduos conhecerem a dramaturgia, unindo, assim, a vocação dessa instituição para o literário (em que outro espaço tantas pessoas têm a oportunidade de interagirem com os textos literários?) e para o artístico, dois aspectos que, como vimos no decorrer do trabalho, unem-se nas atividades que propomos.

\section{Referências}

BRAZ, Júlio Emílio. Uma ratinha apaixonada. Ilustrações de Maurício Veneza. Curitiba: Positivo, 2010.

HUNT, Peter. Crítica, teoria e literatura infantil. Tradução de Cid Knipel. São Paulo: Cosac Naify, 2010.

JAPIASSU. Ricardo. Depoimentos de professores brasileiros. In: SPOLIN, Viola. Jogos teatrais: o fichário de Viola Spolin. São Paulo: Perspectiva, 2001. 
KOUDELA, Ingrid. Jogos teatrais. São Paulo: Perspectiva, 2006.

KOUDELA, Ingrid. Parecer. São Paulo, 2015.

KUHNER, Maria Helena. As aventuras de um Diabo Malandro. Teatro para crianças e jovens. Rio de Janeiro: Vertente Cultural, 2011. p. 31-62.

LOBO, Andréa Maria Favilla. A leitura dramática na formação do artista docente. Moringa: artes do espetáculo, João Pessoa, v. 2, n. 2, jul./dez. 2011, p. 41-52. Disponível em: http://periodicos.ufpb.br/ojs2/index.php/moringa. Acesso em: 12 jan. 2019.

MACHADO, Maria Clara. O cavalinho azul. In: MACHADO, Maria Clara. O cavalinho azul e outras peças. Rio de Janeiro: Nova Fronteira, 2009. p. 788.

METZLER, Marta. Leitura dramatizada: objeto de fruição - instrumento de estudo. In: CONGRESSO DE PESQUISA E PÓS-GRADUAÇÃO EM ARTES CÊNICAS, 4., Rio de Janeiro, 2006. Anais [...]. Rio de Janeiro, 2006, p. 231-232.

NAZARETH, Carlos Augusto. O menino detrás das nuvens. Rio de Janeiro: Editora Didática e Científica, 1997.
NAZARETH, Carlos Augusto. O menino detrás das nuvens. Ilustrações de Dani D' Angeli. Erechim: Habilis Press, 2014.

NIKOLAJEVA, Maria; SCOTT, Carole. Livro ilustrado: palavras e imagens. Tradução de Cid Knipel. São Paulo. Cosac Naify, 2011.

PAVIS. Patrice. Dicionário de teatro. São Paulo: Perspectiva, 2007.

REVERBEL, Olga. A herança. In: A chave perdida. Porto Alegre: L\&PM, 1995. p. 59-65.

SAVARY, Flávia. A Rosa que gira a roda. llustrações de Rosinha. Belo Horizonte: Dimensão, 2011.

SAVARY, Flávia. Meus olhos são teus olhos. llustrações de Alexandre Rampazo. Curitiba: Positivo, 2011.

SPOLIN, Viola. Jogos teatrais: o fichário de Viola Spolin. São Paulo: Perspectiva, 2001.

SPOLIN, Viola. Improvisação para o teatro. Tradução de Ingrid Koudela. São Paulo: Perspectiva, 2008.

VIANA, Maria. Festa no céu. Ilustrações de Mateus Rios. Curitiba: Positivo, 2013.

ZIRALDO. Bonequinha de pano. São Paulo: Melhoramentos, 2005.

\section{COMO CITAR ESSE ARTIGO}

GRAZIOLI, Fabiano Tadeu. Leitura dramática e jogo teatral a partir da dramaturgia para crianças e jovens: possibilidades de fruição na escola. Signo, Santa Cruz do Sul, v. 45, n. 82, jan. 2020. ISSN 1982-2014. Disponível em: $\quad$ <https://online.unisc.br/seer/index.php/signo/article/view/14129>. doi:https://doi.org/10.17058/signo.v45i82.14129.

Acesso em: 